\title{
Crecimiento y supervivencia de larvas $D$, pedivéligeras y postlarvas de Gari solida (Mollusca: Psammobiidae), provenientes de reproductores acondicionados
}

Growth and survival of Gari solida (Mollusca: Psammobiidae) D larvae, pediveliger larvae and postlarvae from conditioning broodstock

\author{
Ramiro A. Contreras-Guzmán', Claudia E. Puebla-Arce', Elisa G. \\ Pacheco-Sánchez ${ }^{1}$ y Francisco J. Contreras-Saldaña ${ }^{1}$
}

\begin{abstract}
'Instituto de Ciencia y Tecnología, Universidad Arturo Prat, Ejército 443, Puerto Montt, Chile. ramiro.contreras@unap.cl
Abstract.- Adults of Gari solida were maintained at a room temperature of around $14^{\circ} \mathrm{C}$ for approximately 90 days, fed with a microalgae mix 300,000 cell ml-1, after which spawning was induced in 20 specimens. The oocytes obtained were fertilized at a 10:1 sperm/oocyte ratio and the embryos were incubated in a specially designed system ('hatching system') for a period of $96 \mathrm{~h}$, until D-shape larvae without gelatinous coating were obtained. Larval culture was undertaken in cylindrical $200 \mathrm{~L}$ tanks at $13 \pm 1.3^{\circ} \mathrm{C}$, with seawater filtered to $1 \mu \mathrm{m}$ and $\mathrm{UV}$ irradiation, at an initial density of 9.7 larvae $\mathrm{ml}^{-1}$, with water renewal every 2-3 days; D-shape larvae were fed with Isochrysis aff. galbana and throughout the umbonate, pediveliger and postlarval stages, with a mix of Isochrysis aff. galbana and Chaetoceros calcitrans (7:3), where concentration was proportioned in accordance with culture density. The umbonate larval stage was detected at day 11 of culture and the pediveliger stage, at day 22, starting from the free-swimming D-shape larvae. Metamorphosis was induced with an epinephrine bath at $0.005 \mathrm{~N}$ concentration and postlarvae obtained at day 26 of culture were subsequently cultured up to day 35. Average sizes reached were $122 \pm 13 \mu \mathrm{m}, 158 \pm 12 \mu \mathrm{m}, 185 \pm 5 \mu \mathrm{m}$ and $216 \pm 24 \mu \mathrm{m}$ for the ' $D$ ', umbonate, pediveliger and postlarval stages, respectively. Survival up to postlarvae stage was $0.005 \%$. Development of G. solida larvae and postlarvae culture is in its initial phases and improvements in all stages are necessary, from breeder conditioning onwards.
\end{abstract}

Key words: Bivalves, larval development, clams

\section{INTRODUCCIÓN}

Gari solida (Gray, 1928), denominado comúnmente 'culengue', es un molusco bivalvo que se distribuye desde Perú $\left(14^{\circ} \mathrm{S}\right)$ hasta el extremo sur de Chile $\left(54^{\circ} \mathrm{S}\right)$ (Urban 1994) y que se encuentra a menudo compartiendo hábitat con otros bivalvos enterradores como Semele solida Gray, 1828 y Protothaca thaca Molina, 1782 (Urban \& Campos 1994).

La especie sustenta una importante pesquería artesanal en la Región de Los Lagos, Chile (Asencio et al. 1996, Jerez et al. 1999, Romero et al. 2011), la que concentró más del $80 \%$ del desembarque total en el periodo 1980 a

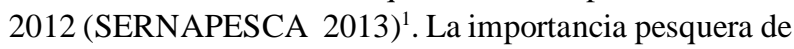
G. solida, conjuntamente con una disminución de sus desembarques a partir de la década de los noventa, generó interés por su cultivo, efectuándose dos proyectos orientados a generar la tecnología de su cultivo (FONDEF, Chile) $)^{2,3}$. Con anterioridad Olavarría et al. (1996), informan sobre la morfometría de larvas D, pedivelígeras y postlarvas de G. solida en cultivos en laboratorio que se efectuaron a partir de emisiones gaméticas de reproductores no acondicionados y Contreras et al. (2014) informan sobre el desarrollo embrionario de la especie. El presente trabajo, se desarrolló en el marco de un proyecto de producción de semilla de G. solida a nivel semi productivo $^{3} \mathrm{y}$ tiene por objetivo informar el crecimiento y supervivencia de larvas y post larvas de la especie, obtenidas a partir de un desove de reproductores acondicionados.

\footnotetext{
${ }^{1}$ SERNAPESCA. 2013. Anuarios Estadísticos de Pesca 1980-2011. Servicio Nacional de Pesca, Valparaíso. <http:// www.sernapesca.cl/index.php?option=com_remository\&Itemid $=54 \&$ func $=$ select\&id=2>

2Proyecto FONDEF D03 11156 'Desarrollo de la tecnología de cultivo del recurso culengue (Gari solida) en la zona centro sur de Chile'. 3Proyecto FONDEF D08 I1011 'Optimización del cultivo de semilla de culengue (Gari solida), enfocada al cultivo de engorda'.
} 


\section{Materiales Y MÉTODOS}

Ejemplares adultos de G. solida de entre 50-60 mm de longitud valvar $(\mathrm{n}=158)$, capturados mediante buceo en la localidad de Carelmapu, Chile ( $41^{\circ} 44^{\prime} \mathrm{S}$; $73^{\circ} 42^{\prime} \mathrm{W}$ ), fueron ingresados al laboratorio de la empresa Cultivos Mario Cerna (comuna de Chonchi, Chiloé, Chile). Se sacrificaron 15 animales de este grupo (ca., 10\%) para determinar su estado de madurez gonadal inicial, utilizando la escala macroscópica descrita por Contreras et al. (2014), determinando que el $40 \%$ de los reproductores ingresaron al criadero en estado 0 (inmaduro) y el $60 \%$ en estado 1 (madurez inicial o regresión). De los restantes ejemplares $(n=143), 80$ individuos fueron dispuestos en 1 estanque circular de $200 \mathrm{~L}$ (123 cm de diámetro y $50 \mathrm{~cm}$ de altura), provisto de una capa de arena de $20 \mathrm{~cm}$. En los primeros 10 días, desde su ingreso al laboratorio, se mantuvieron con agua circulante, sin alimentación, a temperatura ambiente cercana a $14^{\circ} \mathrm{C}$ y posteriormente, se les proporcionó una mezcla de microalgas Isochrysis aff. galbana (T-Iso), Chaetoceros calcitrans y Tetraselmis suecica en proporción 1:1:1 a una concentración de 300.000 cél ml$^{-1}$. Durante el acondicionamiento gonádico y antes de la inducción al desove, se sacrificaron periódicamente animales para evaluar el desarrollo de la gónada según el método de observación macroscópica señalado anteriormente. Cuando el $50 \%$ de los animales muestreados se encontraba en estado 3 (maduros), lo cual ocurrió cercano a los 90 días desde su ingreso al criadero, se indujo el desove a 20 ejemplares utilizando el método de choque térmico y desecación según Contreras et al. (2014). Una vez comenzado el desove, los ejemplares fueron colocados individualmente en recipientes de $1 \mathrm{~L}$, con agua de mar a temperatura ambiente y los ovocitos obtenidos se fertilizaron en proporción de 10:1 espermatozoides/ovocito, contabilizando en 3 alícuotas tanto a los ovocitos y espermatozoides en una cámara de Sedgewick Rafter y de Neubauer, respectivamente. Los embriones fueron incubados en un sistema de circulación cerrado compuesto por dos estanques cilíndricos de $200 \mathrm{~L}$ dispuestos en serie en la vertical y conectados por una tubería de PVC de 32 $\mathrm{mm}$ de diámetro; el de abajo provisto de un grupo de tamices de 150, 60 y $45 \mu \mathrm{m}$ (bajo la tubería de PVC) y de una bomba de acuario conectada a un tubo que permitió elevar agua al estanque superior (Fig. 1). Este sistema de incubación se diseñó debido a que los embriones mantienen una cubierta gelatinosa hasta el estado de larva $\mathrm{D}$, lo que aumenta su diámetro y volumen, resultando imposible separar las larvas D sin cubierta (aptas para alimentarse y nadar libremente), de aquellas que no logran 'eclosionar' desde esta cubierta. Una vez que las larvas D pierden la cubierta gelatinosa, son capaces de nadar libremente, pasar por el tubo que

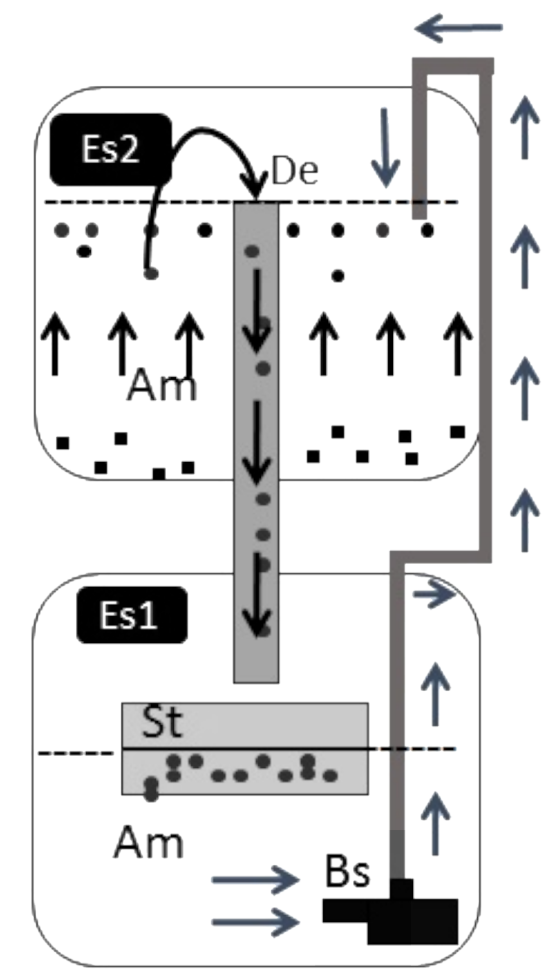

Figura. 1. Sistema de incubación para embriones de G. solida. La bomba (Bs) impulsa el agua de mar (Am) desde el estanque 1 (Es1) al estanque 2 (Es2); del Es2 al Es1 el agua de mar cae por gravedad. Los círculos negros representan larvas libre nadadoras que son retenidas en el set de tamices (St) y los cuadrados negros a los embriones y/o larvas que se mantienen dentro de la cubierta gelatinosa. El nivel del agua de mar se indica con una línea punteada en ambos estanques / Incubation system for G. solida embryos. The pump (Bs) drives the seawater (Am) from pond 1 (Es1) to basin 2 (Es2); Es2 to Es1 of seawater falls by gravity. The black circles represent free-swimming larvae that are retained on the set of sieves (St) and the black squares embryos and / or larvae that remain in the gelatinous covering. The sea water level is indicated by a dotted line in both ponds

comunica ambos estanques y quedan retenidas principalmente en el tamiz de $60 \mu \mathrm{m}$. Este sistema se mantuvo sin aireación, a temperatura ambiente que varió entre $14 \pm 0,8^{\circ} \mathrm{C}$, sin recambio de agua pero circulando entre ambos estanques, por un periodo de 96 h (4 días), hasta que la mayor parte de las larvas quedaron retenidas en el tamiz de $60 \mu \mathrm{m}$, constatándose libres de la cubierta y con capacidad natatoria. Las larvas así obtenidas fueron dispuestas en 2 estanques de $200 \mathrm{~L}$, a una densidad inicial de 9,7 larvas $\mathrm{ml}^{-1}$, a temperatura ambiente $\left(13 \pm 1,3^{\circ} \mathrm{C}\right)$ y con recambios totales cada 2 días. La alimentación de las larvas consistió en microalgas proporcionadas diariamente a una concentración inicial de 43.000 cél. $\mathrm{ml}^{-1}$ y que varió 
posteriormente, dependiendo de la etapa y densidad del cultivo. Hasta el día 10 sólo se proporcionó Isochrysis aff. galbana y desde el día 11 al 35, durante el estado de umbonadas, pedivelígeras y posteriormente como postlarvas, se alimentaron con una mezcla de Isochrysis aff. galbana y Chaetoceros calcitrans (7:3). Se indujo a larvas pedivelígeras a la metamorfosis, mediante baño de una hora con epinefrina $0,005 \mathrm{~N}$ (Helm et al. 2006). Las postlarvas obtenidas fueron mantenidas en bandejas con sustrato de arena fina, a temperatura ambiente de $13 \pm 0,3^{\circ} \mathrm{C}$, con aireación suave y la alimentación ya señalada. En todas las fases y procedimientos del cultivo, se utilizó agua de mar filtrada a $1 \mu \mathrm{m}$ e irradiada con luz ultravioleta.

Se evaluó el crecimiento de las larvas durante los recambios de agua, reteniéndolas en tamices adecuados a su tamaño. Luego se llevaron a un volumen conocido de agua de mar, donde se homogeneizaron y se tomaron muestras de $1 \mathrm{ml}$ que fueron depositadas en una cámara de Sedgewick Rafter y observadas utilizando un microscopio óptico de campo, equipado con un ocular graduado y una cámara Moticam 2500 para el registro fotográfico. Para la medición de las larvas, se utilizó el software de imagen Motic® Images Plus versión 2.0, midiendo la mayor distancia entre el borde anterior y posterior de la concha, de entre 10 a 15 individuos en cada muestra. La tasa de crecimiento se estimó como el aumento de la longitud de la concha por unidad de tiempo (Olavarría et al. 1996). El porcentaje de supervivencia se obtuvo contando las larvas vivas desde una sola muestra de $1 \mathrm{ml}$ utilizando la cámara de Sedgewick Rafter; este dato se dividió por el número de larvas contadas al inicio multiplicado por 100. Los datos fueron tabulados y procesados utilizando la estadística descriptiva del programa Excel Microsoft ${ }^{\circledR}$ Office 2007.

\section{RESULTADOS Y DISCUSIÓN}

La inducción al desove resultó exitosa en el $40 \%$ de los animales, desovando 5 machos y 3 hembras. El desove produjo un total de 4.146 .000 ovocitos, en promedio $1,4 \pm$ 0,71 millones por hembra; el porcentaje de fertilización fue de $96 \%$.

Al cuarto día de incubación, 96 h post-fertilización, el 97\% de las larvas presentes en el cultivo correspondieron a larvas D, con capacidad de desplazamiento en la columna de agua. (Fig. 2a). La larva D se mantuvo por alrededor de 7-10 días; al día 11 del cultivo larvario, fue posible distinguir el umbo y al día 13 más del $90 \%$ de las larvas presentaban una clara curvatura en la región de la charnela indicando el estado de larva umbonada (Fig. 2b); la larva pedivelígera se constató el día 22 a partir del inicio del cultivo larvario; en este estado se observó el desarrollo del pie y disminuyó considerablemente el tamaño del velo (Fig. 2c). La inducción a la metamorfosis se efectuó el día 25 y el estado de post larva se constató en el día 26, con más del $90 \%$ de las larvas metamorfoseadas (Fig. 2d).

La larva D al inicio de la etapa tuvo una longitud promedio de $109 \pm 3 \mu \mathrm{m}$ y al final $135 \pm 7 \mu \mathrm{m}$, siendo la duración de esta etapa de aproximadamente 10 días. La larva umbonada al inicio de la etapa tiene una longitud promedio de $141 \pm 4 \mu \mathrm{m}$ y al final $175 \pm 7 \mu \mathrm{m}$, con una duración de esta etapa de aproximadamente 8 días. Las larvas pedivelígeras alcanzaron en promedio $185 \pm 13 \mu \mathrm{m}$ de longitud y su duración fue de aproximadamente 4 días. Las postlarvas, al inicio de la etapa, tienen una longitud promedio de $190 \pm 18 \mu \mathrm{m}$, las que tras 9 días alcanzaron los $236 \pm 8 \mu \mathrm{m}$. La longitud promedio alcanzada para los estados de larva $\mathrm{D}$, umbonada, pedivelígera y postlarva, fue $122 \pm 13 \mu \mathrm{m}, 158 \pm 12 \mu \mathrm{m}, 185 \pm 5 \mu \mathrm{m}$ y $216 \pm 24 \mu \mathrm{m}$, respectivamente (Tabla 1 ).

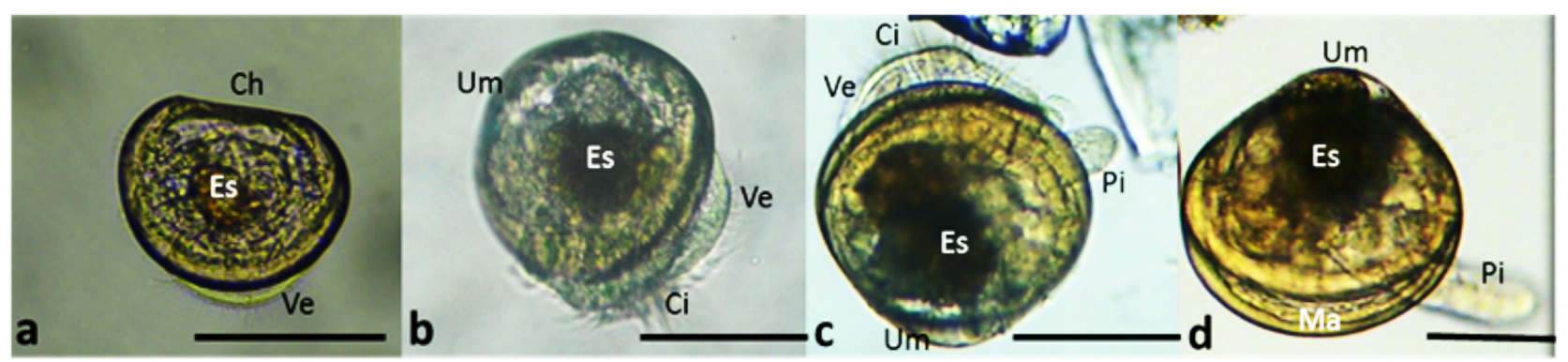

Figura 2. Estados larvarios de G. solida. (a) larva D; (b) larva umbonada; (c) pedivelígera y (d) post larva. Escala $100 \mu \mathrm{m}$. Es: estómago, Ch: charnela, Ve: velo, Um: umbo, Ci: cilios, Pi: pie, Ma: manto / G. solida larvae stages. (a) D-shape larva; (b) umbonate larva; (c) pediveliger larva and (d) post larva. Scale bar $100 \mu \mathrm{m}$. Es: stomach, Ch: charnela, Ve: velum, Um: umbo, Ci: cillia, Pi: foot, Ma: mantle 
Tabla 1. Longitud promedio $(\mu \mathrm{m})$, tiempo de cultivo (días) y crecimiento promedio ( $\mu \mathrm{m}$ día $^{-1}$ ) de larvas y post larvas de G. solida en el cultivo experimental / Average length $(\mu \mathrm{m})$, culture period (days) and average growth $\left(\mu \mathrm{m} \mathrm{day}^{-1}\right)$ of $\mathrm{G}$. solida larvae and postlarvae in the experimental culture

\begin{tabular}{lccccc}
\hline Estado & $\begin{array}{c}\text { Tiempo de } \\
\text { cultivo } \\
\text { (días) }\end{array}$ & $\begin{array}{c}\text { Longitud } \\
\text { promedio } \\
(\mu \mathrm{m})\end{array}$ & $\mathrm{DE}$ & $\mathrm{n}$ & $\begin{array}{c}\text { Crecimiento } \\
\text { promedio } \\
\left(\mu \mathrm{m} \mathrm{día}^{-1}\right)\end{array}$ \\
\hline Larva D & 0 & 109 & 5 & 15 & \\
Larva umbonada & 3 & 121 & 9 & 15 & 4,1 \\
& 11 & 135 & 7 & 15 & 3,5 \\
& 13 & 141 & 4 & 15 & 1,6 \\
& 15 & 154 & 3 & 15 & 6,7 \\
Larva pedivelígera & 17 & 164 & 7 & 12 & $-0,4$ \\
Postlarva & 19 & 175 & 7 & 13 & 5,1 \\
& 22 & 185 & 5 & 13 & 5,4 \\
& 32 & 190 & 18 & 10 & 1,1 \\
& 35 & 221 & 9 & 15 & 5,2 \\
& 236 & 8 & 15 & 5,2 \\
\hline
\end{tabular}

La longitud promedio en función del tiempo de las larvas y postlarvas en el cultivo experimental, siguió una relación lineal $\left(\mathrm{R}^{2}=0,951 ; P<0,05\right)$ (Fig. 3). La tasa de crecimiento fluctuó entre $3,4 \mu \mathrm{m} \mathrm{día}{ }^{-1}$ para el estado pedivelígera y $3,8 \mu \mathrm{m}$ día $^{-1}$ para los estados de larva $\mathrm{D}$ y postlarvas; mientras que el máximo crecimiento promedio por día $\left(6,7 \mu \mathrm{m} \mathrm{día}^{-1}\right)$ se produjo en la fase de larva umbonada entre el día 11 y 13 (Tabla 1 ).

La supervivencia de las larvas D hasta el estado de pedivéligera, justo antes de la inducción a metamorfosis, alcanzó al 14\%. A los 35 días de cultivo, 8 días posteriores a la inducción a metamorfosis, disminuyó a 0,005\% (Fig. 4).

En el presente trabajo fue posible acondicionar ejemplares de G. solida en el laboratorio, durante invierno (julio a septiembre), época del año que no corresponde al periodo de madurez natural de la especie, en la zona sur de Chile, según se señala en estudios sobre su ciclo reproductivo (Asencio et al. 1996, Jerez et al. 1999, Jaramillo et al. 2003). Muchos bivalvos de aguas templadas y frías requieren entre 4 y 8 semanas de acondicionamiento para alcanzar la madurez suficiente para desovar a finales de invierno y principios de primavera (Helm et al. 2006), pero la condición gametogénica inicial de los reproductores puede demorar la maduración. En el venérido Ruditapes decussatus, se obtuvo individuos maduros en 14 semanas de acondicionamiento partiendo desde reposo gonadal en época de otoño, manejando la alimentación y la temperatura constante en un gradiente hasta $20^{\circ} \mathrm{C}$, no resultando aconsejable desde el punto de vista productivo realizar acondicionamiento a partir del reposo gonadal (Ojea 2013). En los solénidos, Ensis siliqua, Ensis arquatus y Solen marginatus, partiendo desde reposo gonadal, no se consiguió adelantar sustancialmente la maduración y puesta con el acondicionamiento, pero partiendo desde gametogénesis avanzada en E. siliqua y $S$. marginatus, se consigue adelantar la maduración en 2 meses respecto al medio natural, proporcionando alimentación y aumento gradual de temperatura de 17 a $25^{\circ} \mathrm{C}$ (Da Costa 2009). En este estudio, el tiempo de acondicionamiento para G. solida fue de 13 semanas, a temperatura ambiente relativamente estable y cercana a los $14^{\circ} \mathrm{C}$ durante todo el periodo, consiguiendo madurez en el $40 \%$ de los ejemplares y entre 2 a 3 meses antes respecto a lo que ocurre en el medio natural.

Estos resultados son interesantes y susceptibles de optimizar. Eventualmente, un mayor manejo de la temperatura podría disminuir el tiempo de acondicionamiento para G. solida. En la mayoría de los bivalvos, el incremento de temperatura favorece la 


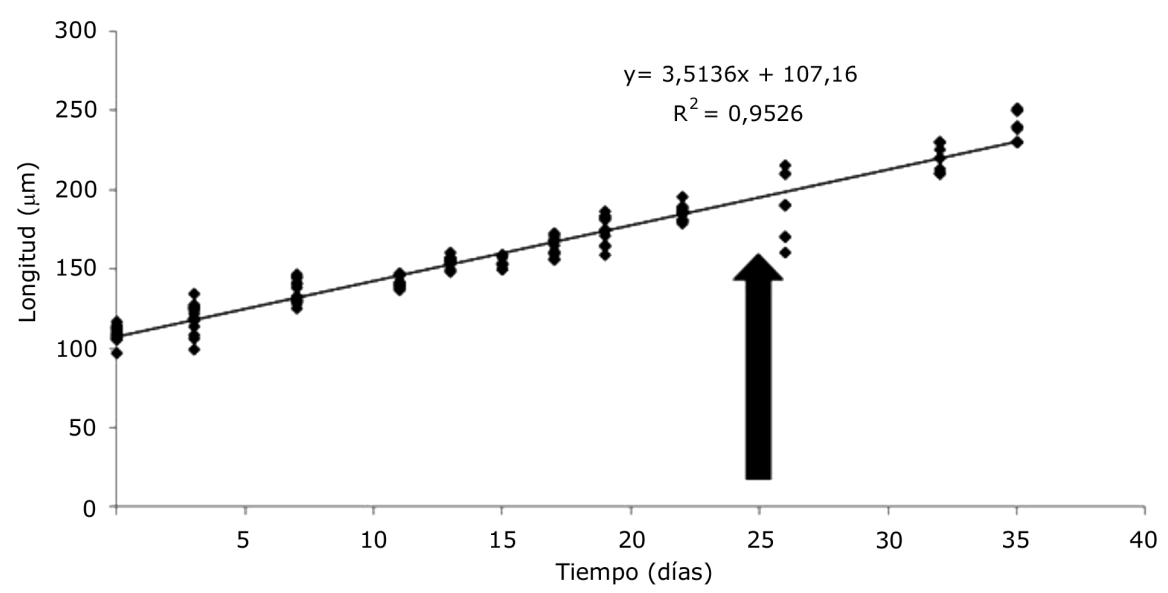

Figura 3. Longitud promedio $(\mu \mathrm{m})$ de larvas y postlarvas de G. solida en función del tiempo de cultivo (días), a partir de larva ' $D$ ' sin cubierta gelatinosa. La flecha indica la inducción a metamorfosis / Average length $(\mu \mathrm{m})$ of $\mathrm{G}$. solida larvae and postlarvae over culture period (days), starting from ' $\mathrm{D}$ ' larvae without gelatinous cover. The arrow indicates the induction of metamorphosis

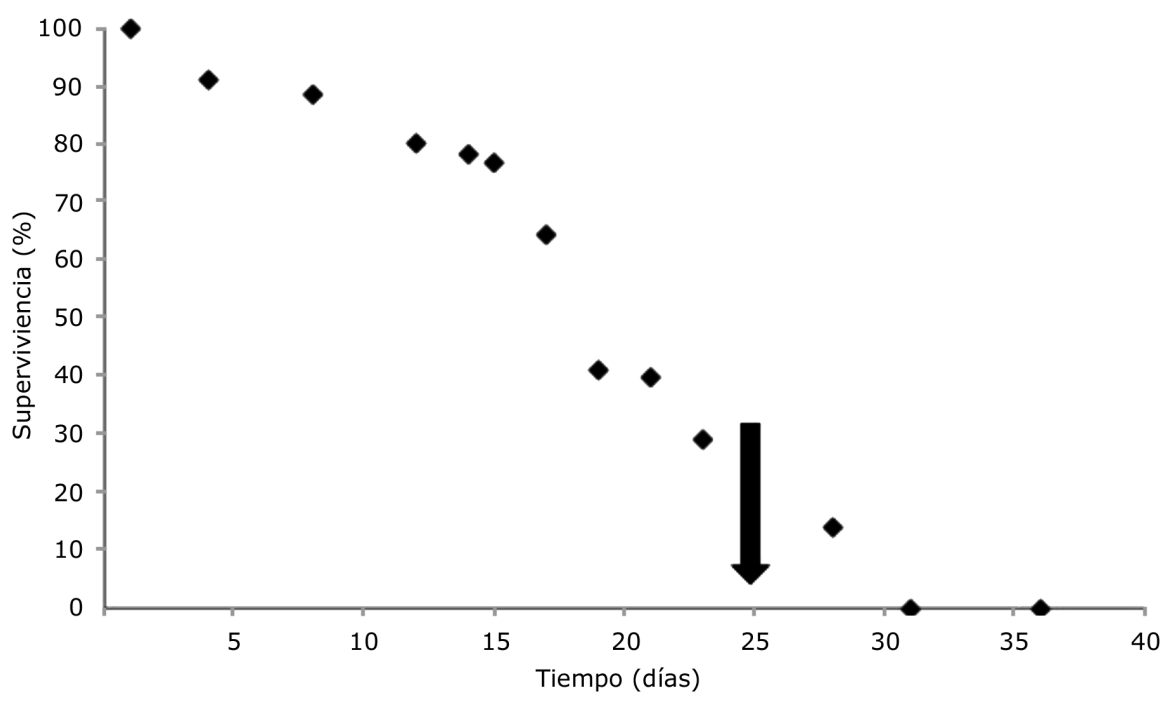

Figura 4. Supervivencia del cultivo larvario y postlarvario de G. solida. La flecha indica la inducción a metamorfosis / Survival of larval and post-larval culture of G. solida. The arrow indicates the induction of metamorphosis 
vitelogénesis (Robinson 1992); sin embargo, en algunas especies como ostión del norte (Argopecten purpuratus), el acondicionamiento con un tratamiento a temperatura constante de $15^{\circ} \mathrm{C}$ resultó en mayor porcentaje de desove, mayor liberación de gametos, mayor tamaño y mejor viabilidad de larvas que tratamientos de temperatura $19^{\circ} \mathrm{C}$ constante, aumento de 15 a $19^{\circ} \mathrm{C}$ y disminución de 19 a $15^{\circ} \mathrm{C}$, en un mismo período de tiempo de 38 días (Martínez \& Pérez 2003).

El desove en bivalvos puede producir un número variable de ovocitos, dependiendo del tamaño del adulto, su condición y otros factores (Navarro et al. 1991). La fecundidad potencial de G. solida, ha sido estimada entre 4,9 y 16,8 millones de ovocitos maduros por hembra para ejemplares entre 52,4 y 74,6 mm, respectivamente (Asencio et al. 1996).

El número promedio de ovocitos emitidos por hembra en este estudio fue aproximadamente de 1,4 millones, lo que está dentro del rango de 1 a 4 millones de huevos promedio por hembra, obtenidos en laboratorio por estos autores en diversos desoves. En el venérido Ruditapes decussatus, Pérez-Camacho et al. (1977) reportaron 1 millón y Aranda (2010) 1,8 millones. Para la almeja babosa, Venerupis pullastra, se reportan un número variable entre 0,36 a 1,9 millones de ovocitos promedio por hembra (Ojea et al. 2013).

La etapa de incubación de bivalvos de cultivo como venéridos y pectínidos, suele ser de 24 a 48 h dependiendo de la especie y de la temperatura de cultivo (Helm et al. 2006). En este estudio, esta etapa fue de $96 \mathrm{~h}$ (4 días a $14 \pm 0,8^{\circ} \mathrm{C}$ ). La cubierta gelatinosa que rodea al ovocito y a la larva temprana de G. solida, condujo a diseñar un sistema de incubación mediante el cual fue posible obtener un porcentaje de larvas D 'eclosionadas' desde la cubierta gelatinosa, de $97 \%$ respecto al número inicial de embriones incubados, lo que está por sobre el rango de larvas D que se obtiene regularmente a partir del cultivo de embriones, el que puede ir desde un 30 a $85 \%$ (Helm et al. 2006). Esta cubierta, ha sido reportada para el semélido Scrobicularia plana dónde se mantiene hasta el estado de larva D, entre 2,5 a 4 días post-fertilización (dpf) (Frenkiel \& Mouëza 1979) o 48 a 56 h post fertilización (hpf) (Raleigh \& Keggan 2007). En otras especies como en el lucínido Codakia orbicularis (Gros et al. 1997), la cubierta se mantiene en el estado de larva D, hasta $48 \mathrm{hpf}$ (a $25-27^{\circ} \mathrm{C}$ ), y en el solénido Solen marginatus hasta 12 y $24 \mathrm{hpf}\left(\mathrm{a} 19 \pm 1^{\circ} \mathrm{C}\right)(\mathrm{Da}$ Costa 2009$)$.
En este estudio, el desarrollo de Gari solida desde la etapa de larva D libre nadadora hasta la metamorfosis (inducida) se completó en 26 días, lo que sumado a los 4 días de incubación dio como resultado 30 días de desarrollo desde la fertilización a la metamorfosis (ca., $14^{\circ} \mathrm{C}$ ). Esta cifra es similar a la obtenida por Olavarría et al. (1996) para esta misma especie, quienes reportan poco más de 30 días de duración del desarrollo larvario a temperatura ambiente en el mes de noviembre en Putemún (Chiloé, Chile). Por otra parte, la longitud promedio de las larvas y postlarvas en función del tiempo, se ajusta a una relación lineal en ambos estudios, pero con importantes diferencias en los tamaños. Así, la longitud promedio de las larvas D del presente estudio $(122 \pm 13 \mu \mathrm{m})$ es superior a la que señala Olavarría et al. (1996) $(98 \mu \mathrm{m})$ y el de las pedivelígeras por el contrario, es inferior en el presente estudio $(185 \pm 5 \mu \mathrm{m})$ que en el de los autores señalados $(266 \mu \mathrm{m})$. La longitud promedio a metamorfosis señalada por Olavarría et al. (1996) $(266,04 \pm 2,37 \mu \mathrm{m})$ es mayor a la talla promedio de metamorfosis de este estudio (190 \pm 18 $\mu \mathrm{m})$, de manera que incluso las post larvas de 30 a 35 días del presente estudio, son de tamaño inferior $(216 \pm 24 \mu \mathrm{m})$ a las pedivelígeras obtenidas por Olavarría et al. (1996). Las distintas metodologías de cultivo (i.e., origen y condición gametogénica de los reproductores, densidad de cultivo, concentración del alimento, calidad del agua, así como el efecto de la inducción a metamorfosis, entre otros), pudieron incidir en las diferencias entre ambos estudios.

La tasa de crecimiento y supervivencia de larvas y postlarvas de bivalvos que se cultivan en criadero, pueden ser influidas por la calidad de los ovocitos (Padilla \& Olivares 1986, Avendaño et al. 2001, Farías 2008, Da Costa 2009), temperatura (Lagos et al. 2012), calidad del agua del cultivo y condiciones de alimentación (Helm et al. 2006). La tasa de crecimiento larvario varía también entre distintas familias de bivalvos, siendo por ejemplo, mayor en ostreídos que en pectínidos y venéridos (Helm et al. 2006).

En el presente estudio la tasa de crecimiento en el periodo larvario $\left(3,5 \mu \mathrm{m} \mathrm{dia}{ }^{-1}\right.$ a $\left.13^{\circ} \mathrm{C}\right)$ fue menor a la obtenida por Avendaño et al. (2001) (6,59 y 7,61 $\mu \mathrm{m} \mathrm{día}^{-1}$ a 19,5-21,5 $\left.{ }^{\circ} \mathrm{C}\right)$ en 2 de 6 cultivos larvarios de Argopecten purpuratus, y similar a los efectuados por Pérez-Camacho et al. (1977) en Venerupis pullastra $\left(3 \mu \mathrm{m}\right.$ día $^{-1}$ a $\left.14^{\circ} \mathrm{C}\right)$. La temperatura de cultivo y el grupo taxonómico de la especie, entre otras variables, podrían explicar las diferencias de este estudio con Avendaño et al. (2001), así como la semejanza con 
Pérez-Camacho et al. (1977). Una de las variables ambientales más relevantes para el crecimiento de invertebrados marinos es la temperatura ya que pequeños incrementos durante la fase exponencial de crecimiento son suficientes para generar grandes diferencias en la relación talla-edad (Pecl et al. 2004). Para el desarrollo de cultivos larvarios, es de importancia establecer límites de tolerancia a esta variable, ya que a altas temperaturas de cultivo se suele reportar alta mortalidad (Ansell 1961).

En este estudio la supervivencia larval alcanzó a 14\%, superior a la de Argopecten purpuratus (2,35 a 5,7\%) (Avendaño et al. 2001) e inferior a la supervivencia de Ruditapes philippinarum (52\%) (Yan et al. 2006) y por lo tanto dentro de los rangos señalados para otros bivalvos.

La baja supervivencia postlarvaria, que descendió notoriamente a los 30 días de cultivo $(0,002 \%)$, es posible que se deba al efecto de la inducción a metamorfosis (epinefrina $0,005 \mathrm{~N}$ ) ya que no se detectó otro evento que haya afectado el normal desarrollo del cultivo.

\section{Agradecimientos}

Se agradece a la Comisión Nacional de Ciencia y Tecnología, CONICYT, quien a través de su Programa FONDEF, financió este estudio. A la empresa Cultivos Mario Cerna, por permitir el uso de sus instalaciones para el desarrollo de este estudio.

\section{LITERATURA CITADA}

Ansell AD. 1961. Reproduction, growth and mortality of Venus striatula (da Costa) in Kames Bay, Millport. Journal of Marine Biological Association of the United Kingdom 41: 191-215.

Asencio V, E Lozada \& A Reyes. 1996. Aspectos reproductivos Culengues X Región. IFOP-FNDR- BIP 30087631. En: Barahona N, A Olguín, C Vicencio, V Pezo \& L Ariz. 2006. Programa de Seguimiento del Estado de Situación de las Principales Pesquerías Nacionales. Proyecto: Investigación Situación Pesquerías Bentónicas 2005: 1-133. IFOP, Valparaíso.

Avendaño M, M Le Pennec \& M Cantillanez. 2001. Anormalidades en larvas de Argopecten purpuratus (Lamarck, 1819) (Mollusca: Pectinidae), uno de los problemas en la producción artificial de semilla. Estudios Oceanológicos 20: 33-42.

Contreras R, E Pacheco \& C Puebla. 2014. Desarrollo embrionario y larval temprano de Gari solida (Gray, 1828)(Bivalvia: Psammobiidae). Latin American Journal of Aquatic Research 42(1): 283-288.
Da Costa F. 2009. Optimización del cultivo en criadero de navaja (Ensis arcuatus Jeffreys, 1865), longueirón (E. siliqua Linneo, 1758) y longueirón vello (Solen marginatus Pennánt, 1777): composición bioquímica y de ácidos grasos en los desarrollos larvarios. Tesis Doctoral, Universidad de Santiago de Compostela, Galicia, 336 pp.

Farías A. 2008. Nutrición y alimentación en moluscos bivalvos. En: Lovatelli A, A Farias \& I Uriarte (eds). Estado actual del cultivo y manejo de moluscos bivalvos y su proyección futura: factores que afectan su sustentabilidad en América Latina. Actas de Pesca y Acuicultura 12: 297-308. FAO, Roma.

Frenkiel L \& M Mouëza. 1979. Développement larvaire de deux Tellinaceae, Scrobicularia plana (Semelidae) et Donax vittatus (Donacidae). Marine Biology 55: 187-195.

Gros O, L Frenkiel \& M Mouëza. 1997. Embryonic, larval, and post-larval development in the symbiotic clam Codakia orbicularis (Bivalvia:Lucinidae). Invertebrate Biology 116(2): 86-101.

Helm M, MN Bourne \& A Lovatelli. 2006. Cultivo de bivalvos en criadero. Un manual práctico. FAO Documento Técnico de Pesca 471: 1-184.

Jaramillo E, O Garrido, C Gallardo \& H Contreras. 2003. Bases biológicas para el ordenamiento de las pesquerías de almeja en la X y XI Regiones. Universidad Austral de Chile. Proyecto FIP No 2001-27. <http://www.fip.cl/Archivos/ Hitos/Informes/inffinal\%202001-27.pdf>

Jerez G, N Barahona, H Miranda, V Ojeda, D Brown, C Osorio, A Olguín \& J Orensanz. 1999. Estudio biológico pesquero de los recursos Tawera (Tawera gayi) y Culengue (Gari solida) en la X Región. Informe Final. FIP 97-29: 1149. < http://www.fip.cl/Archivos/Hitos/Informes/ inffinal\%2097-29.pdf>

Lagos L, I Uriarte, G Yany \& M Astorga. 2012. Effect of temperature on the culture of larvae of the bivalve Mytilus chilensis originated from broodstocks from different latitudes in a controlled environment. Ciencias Marinas 38(3): 543-550.

Martínez G \& H Pérez. 2003. Effect of different temperature regimes on reproductive conditioning in the scallop Argopecten prupuratus. Aquaculture 228: 153-167.

Navarro PF, LF Sturla, OC Contreras \& MD Avendaño. 1991. Argopecten prupuratus. In: Shumway S \& J Parsons (eds): Scallops: biology, ecology and aquaculture. Developments in Aquaculture and Fisheries Science 21: 1001-1014. Elsevier Science Publishers, New York.

Ojea J. 2013. Estudio del desarrollo gametogénico de la almeja fina, Ruditapes decussatus (Linné, 1758) en el medio natural y optimización de las condiciones del acondicionamiento en criadero. Tesis Doctoral, Universidad de Santiago de Compostela, Galicia, 155 pp. 
Olavarría E, A Farías \& I Uriarte. 1996. Morfometría y tasas de crecimiento larvario y postlarvario de los bivalvos Venus antiqua (King y Broderip, 1835) y Gari solida (Gray, 1828) cultivadas en laboratorio. Revista de Biología Marina 31(2): 107-116.

Padilla M \& G Olivares. 1986. Evaluación de la madurez vitelogénica en oocitos extirpados de la almeja Venus antiqua antiqua. Revista de Biología Marina 22(1): 61-74.

Pecl GT, MA Steer \& KE Hodgson. 2004. The role of hatchling size generating the intrinsic size-at-age variability of cephalopods: extending the Forsythe Hypothesis. Marine and Freshwater Research 55: 387-394.

Pérez-Camacho A, J Román \& M Torre. 1977. Experiencias en cultivo de larvas de 3 especies de moluscos bivalvos: Venerupis pullastra (Montagu), Venerupis decusata (Linnaeus) y Ostrea edulis (Linnaeus). Boletín, Instituto Español de Oceanografía 3(235): 6-61.

Raleigh J \& F Keegan. 2007. Embryonic development in the bivalve Scrobicularia plana (Semelidae) using scanning electron microscopy. Invertebrate Reproduction \& Development 50(3): 139-144.
Robinson A. 1992. Gonadal cycle of Crassostrea kumamoto (Thunberg) in Yaquina bay, Oregon and optimum conditions for broodstock oyster and larval culture. Aquaculture 99: 277-284.

Romero MS, W Stotz, P Araya, F Ruiz \& J Aburto. 2011. Estimación de parámetros reproductivos y determinación de parámetros de crecimiento en los recursos almejas y culengue del norte de Chile (Regiones XV, I y II). Informe Final FIP 2008-49: 1-164. <http://www.fip.cl/Archivos/ Hitos/Informes/INFOR ME\% $20 \mathrm{HITO} \% 20 \mathrm{FINAL}$ 256Adjunto1.pdf>

Urban HJ. 1994. Upper temperature tolerance of ten bivalve species off Peru and Chile related to El Niño. Marine Ecology Progress Series 107:139-145.

Urban HJ \& B Campos. 1994. Population dynamics of the bivalves Gari solida, Semele solida and Protothaca thaca from a small bay in Chile at $36^{\circ} \mathrm{S}$. Marine Ecology Progress Series 115: 93-102.

Yan X, G Zhang \& F Yang. 2006. Effects of diet, stocking density and environmental factors on growth, survival and metamorphosis of Manila clam Ruditapes plilippinarum larvae. Aquaculture 253: 350-358. 